\title{
HAMSİ (Engraulis encrasicolus) YAĞINDAN BİYODİZEL ÜRETİMI VE DİZEL MOTOR PERFORMANS VE EMİSYONLARINA ETKİSİ
}

\author{
Yakup SEKMEN $^{1}$, Sedat ŞEN ${ }^{2}$ \\ ${ }^{1}$ Karabük Üniversitesi, Mühendislik Fakültesi, Makine Mühendisliği Bölümü, Karabük \\ ${ }^{2}$ Gaziosmanpaşa Üniversitesi, Tokat Teknik Bilimler Meslek Yüksekokulu, Tokat \\ ysekmen@karabuk.edu.tr, sedat.sen@gop.edu.tr
}

(Geliş/Received: 24.06.2013; Kabul/Accepted: 15.01.2016)

\begin{abstract}
ÖZET
Petrol kaynaklarının sınırlı olması, çevre ile ilgili endişeler, atık ürünlerin değerlendirilmesi ve kirletici emisyonlara getirilen sinırlamalar alternatif yakıt olan biyodizele olan ilgiyi artırmaktadır. Biyodizel, bitkisel, hayvansal ve atık yağlardan üretilebilen; oksijen içerikli, sülfür içermeyen, zehirleyici olmayan, bozunabilir, yüksek setan sayılı ve yağlayıcılık özelliği daha iyi yenilenebilir alternatif bir dizel yakıtıdır. Bu çalışmada, hamsi yağından üretilmiş biyodizel ve dizel yakıtı ile karışımlarının (hacimsel olarak \%5, 20, 50 ve 100), dört zamanlı, tek silindirli bir dizel motorda performans ve egzoz emisyonlarına etkileri tam yük ve değişik devirlerde test edilmiştir. Deneyler sonucunda, karışımdaki biyodizel oranı arttıkça dizel yakıta göre özgül yakıt tüketiminde \%5-12 artış, motor momentinde ise \%2-6 azalma belirlenmiştir. Emisyon testleri sonucunda, CO, $\mathrm{HC}$ ve is emisyonlarında azalma, $\mathrm{NO}_{\mathrm{x}}$ emisyonlarında artış belirlenmiştir.
\end{abstract}

Anahtar Kelimeler: Balık yağı, hamsi yağı, biyodizel, dizel motor, egzoz emisyonları

\section{BIODIESEL PRODUCTION FROM ANCHOVY (Engraulis encrasicolus) OIL AND ITS EFFECT ON DIESEL ENGINE PERFORMANCE AND EMISSIONS}

\begin{abstract}
The interest in biodiesel as an alternative fuel increases due to increasing awareness of the depletion of fossil fuel resources, concerns about the environment, recycling of waste products, and restrictions imposed on exhaust emissions. Biodiesel can be produced from vegetable oils, animal fat or waste cooking oil. Main advantages of biodiesel may be summarized as; biodegradable, sulphur-free, non-poisonous, consisting oxygen and high cetane number and lubricity. In this study, in order to identify performance and exhaust emission characteristics of a four-stroke, single cylinder diesel engine were operated with anchovy oil based biodiesel, diesel fuel and their blends (volumetrically 5, 20,50 and 100\%) at full load and various engine revolutions. We have noted that, increasing the proportion of the biodiesel in the mixture with respect to petroleum based diesel fuel, the specific fuel consumption increases 5-12\%, while engine torque decrease \%2-6. The emission analyses show that the CO, $\mathrm{HC}$ and smoke emission decrease while $\mathrm{NO}_{\mathrm{x}}$ emissions increase.
\end{abstract}

Keywords: Fish oil, anchovy oil, biodiesel, diesel engine, exhaust emissions

\section{GİRIŞ (INTRODUCTION)}

Enerji politikalarında temel alınması gereken unsur, teknolojik ve sosyal gelişmeyi destekleyecek şekilde enerji ihtiyacını karşılamak üzere sürekli, güvenilir, kaliteli, temiz ve ekonomik enerji türlerine yönelmek olmalıdır. Yapılan araştırmalardan, enerji kaynaklarının kullanımında değişiklik yapılmazsa, küresel çapta bir enerji açığının ve çevre kirliliğinin artacağı anlaşıılmaktadır. Dünya enerji ihtiyacının karşılanmasında büyük paya sahip olan petrolün önemli bir kısmı içten yanmalı motorlarda kullanılmaktadır. Otomotiv sektörünün hızla gelişmesi, petrol kaynaklarının sınırlı olması, dünyanın belirli bölgelerinde toplanması ve yanma ürünlerinin çevreye olumsuz etkileri yeni ve temiz 
enerji kaynaklarının araştırılması, verimli kullanması ile yakıt özelliklerinin geliştirilmesi çalışmalarını gündeme getirmiştir [1-3]. İçten yanmalı motorlarda, alkoller, sıvılaştırılmış petrol gazı, sıkıştırılmış veya sıvılaştırılmış doğal gaz, bitkisel ve hayvansal yağlar veya bunlardan üretilen biyodizel alternatif yakitlar olarak kullanılmaktadır. Biyodizel üretiminde doğrudan besin olarak kullanılması mümkün olan bitkisel ve hayvansal yağların yerine, yenilemeyen, yenilmesi zararlı olan, kullanılmış veya atık yağların kullanılması yemeklik yağ ihtiyacının belirli bir bölümünü dışarıdan karşılayan ülkemiz ve bu durumdaki ülkeler için daha uygun olacağ bilinmektedir. Sifir atı gida politikası düşünüldüğünde, dünya genelinde üretilen balığın azımsanmıyacak kısmı atık olarak ayrılmaktadır. Bu bağlamda atık hayvansal yağlar iyi bir seçim olarak görülmektedir. Birleşmiş Milletler Gıda ve Tarım Örgütü (Food and Agriculture Organisation) 2010 verilerine göre Türkiye'de, yakalanarak 486 bin ton, üretilerek 168 bin ton olmak üzere toplam 654 bin ton, dünyada ise toplam 150 milyon ton balık üretimi yapılmaktadır ve işlenen balığın yaklaşık \%50'sinin atık haline (solungaç, yüzgeç, iç organlar ve kafa) geldiğini bildirmektedir [4]. Ayrıca, biyodizel üretim maliyetinin büyük bir kısmını (\%60-75), kullanılan hammadde (yağ ve alkol) oluşturması sebebi ile biyodizel üretiminde yenilemeyen ve atık yağların kullanılması üretim maliyetlerini önemli ölçüde düşürecektir. $\mathrm{Bu}$ ve benzeri nedenlerden ötürü yenilemeyen veya kullanılmış atık hayvansal ve bitkisel yağlardan biyodizel üretimi ve kalitesinin iyileştirilmesine yönelik çalışmalara son zamanlarda önem verildiği görülmektedir [5]. Ancak, bu gelişmelerin yanında bitkisel, hayvansal ve atık yağların hiçbir işleme tabi tutulmaksızın dizel yakıtı ile karışımları yakıtların viskozite, bulutlanma noktası, setan sayısı, 1sıl değeri ve kaynama noktası gibi özelliklerini değiştirmekte ve dizel motorlarda kullanımı önemli problemlere neden olabilmektedir. Dolayısıyla bu yağların dizel motorlarda sorunsuz bir şekilde kullanımlarının sağlanması için bu özelliklerinin dizel yakıtına yakın değerde olması gerekmektedir [6-8]. Hayvansal yağların enerji içerikleri, petrol kökenli dizel yakıtınkine yakın düzeydedir. Fakat yüksek viskozite ve düşük uçuculukları yakıt olarak kullanılmalarını zorlaştırmaktadır. Yüksek viskozite motor yakıt sistemi ve filtresinin tıkanmasına, enjektör açılma basıncının yükselmesine, kötü atomizasyona ve yanma sürelerinin petrol kökenli yakıtlara göre daha uzun olmasina neden olmaktadır [9-11]. Bu sebeple yağlar dizel yakıtı ile belirli oranlarda karıştırılarak seyreltilmekte veya çeşitli yöntemler uygulanarak viskozitesi yeterli seviyeye düşürülmektedir. Viskozitenin düşürülmesinde transesterifikasyon yöntemi sıkça kullanılmakta olup mikroemülsiyon oluşturma, piroliz ve süper kritik yöntemleri de uygulanmaktadır $[12,13]$. Dizel motorlarda biyodizel kullanımının $\mathrm{CO}, \mathrm{HC}$ ve is emisyonlarında azalma sağladığı belirtilmiştir [13, 14]. Biyodizel, yapısında çok az kükürt (S) barındırdığı [15] için yok denecek kadar az $\mathrm{SO}_{2}$ emisyonlarına rastlanmaktadır. Literatürde, biyodizelin yüksek yanma verimi ve egzoz gaz sıcaklığından [16, 17] ve yüksek sıkıştırma direncine sahip olması yanmanın ön karışım fazı esnasında tüketilen yakıt miktarının artışına neden olduğundan (dolaylı püskürtme avansı) $\mathrm{NO}_{\mathrm{x}}$ emisyonlarını yükselttiği bildirilmektedir [18, 19]. Diğer taraftan; yapısında oksijen bulundurması tutuşma gecikmesi süresini kısaltmakta ve biriken yakıtın az olması nedeniyle maksimum sıcaklığı düşürdüğü için ortalama $\mathrm{NO}_{\mathrm{x}}$ emisyonunu azalttığı açıklanmıştır [20, 21]. Önceki çalışmalarda, Büyükkaya (2013) alabalık yağından [22], Şen (2013) hamsi yağından [23], Reyes ve Sepülveda (2006) somon balığı yağından [24], Godiganur vd. (2010) balık yağından [25], Lin ve Li (2009) balık yağı ve atık yemeklik yağdan [21], Gürü vd. (2010) atık tavuk yağından [5], ve Çengelci vd. (2011) hayvansal yağlardan [8] biyodizel üreterek dizel motorda test etmişlerdir. Kaliteli bitkisel yağların biyodizel üretiminde kullanılması, biyodizeli dizel yakıtına göre daha pahalı hale getirmektedir. $\mathrm{Bu}$ nedenle daha düşük maliyetli hammaddelere ihtiyaç duyulmakta ve tercih edilmektedir. İşlenen balığın solungaç, yüzgeç, iç organlar ve kafa gibi kısımları atılmaktadır. Bu çalışmanın amacı, işlenen balığın atık kısımlarının biyodizel kaynağı olarak kullanılabileceğine dikkat çekmek üzere, talep fazlası hamsi yağından dizel yakıtının özelliklerine yakın, temiz ve ucuz alternatif bir yakıt olan biyodizel üretilmiştir. Üretilen biyodizel hacimsel olarak $\% 5, \% 20$ ve $\% 50$ oranında dizel yakıtı ile karıştırılarak ve $\% 100$ olarak tam yük değişik hızlarda (1800-3400 1/min arasında 200 1/min devir aralıklarında) test edilip motor performans ve egzoz emisyonlarına etkileri araştırılmıştır. Böylece, balık atıklarının ve talep fazlası balıkların değerlendirilerek alternatif yakıta dönüştürülmesi ile milli gelire katkı sağlanması, petrolde dışa bağımlılığın ve fosil kökenli yakıtların oluşturduğu kirliliğin azaltılması hedeflenmiştir.

\section{MATERYAL VE YÖNTEM (MATERIAL AND METHOD)}

Balık yağı metil esteri (BYME) üretimi için manyetik karıştırıcılı 1sıtıcı, $5000 \mathrm{~mL}$ 'lik cam beher, 0,001 g hassasiyetli terazi ve termometre kullanılmıştır. Balık yağı Samsun'da bir su ürünleri işletmesinden temin edilmiştir. Biyodizel üretimi için kullanılacak olan yağ içersinde su bulunması ester dönüşümünü olumsuz yönde etkilemektedir [26]. Bu nedenle biyodizel üretimi için ilk olarak balık yağı filtre edildikten sonra sicaklığı $115^{\circ} \mathrm{C}$ 'ye getirilerek içerisindeki su buharlaştırılmıştır. Biyodizel üretiminde \%99 saflıkta metil alkol ve katalizör olarak sodyum hidroksit $(\mathrm{NaOH})$ kullanılmıştır. 1000 mL balık yağ 1 için 4,7 g NaOH, $200 \mathrm{~mL}$ metil alkol içerisinde çözülerek metoksit çözeltisi hazırlanmıştır. 
Yağın sicaklığ $160^{\circ} C^{\prime}$ ye düşürüldükten sonra metoksit çözeltisi ilave edilerek iki saat sabit sıcaklıkta karıştırılmıştır. Reaksiyon sonunda yoğunluğu yüksek olan gliserin ayırma hunisi yardımıyla balık yağı metil esterinden ayrılmıştır. Metil ester içerisindeki katalizör artıklarının temizlenmesi amacıyla üç kez saf 1lık suyla yıkanmıştır. Yıkama sonrası üretilen biyodizel isıtılarak içerisinde mevcut olan su ve alkol uzaklaştırılmıştır. Yağın serbest yağ asitleri oranı ve su içeriği esterleşme reaksiyonunu etkilemektedir. Önceki çalışmalarda yağın asit değerinin $2 \mathrm{mg}$ $\mathrm{KOH} / \mathrm{g}$ 'ın altına düşürülmesi önerilmektedir [27]. Serbest yağ asitleri değerinin \%2'den büyük olması esterleşme verimini azalttığ1 ifade edilmiştir [28]. Ancak, serbest yă asitleri değeri \%5'e kadar olan yağların ilave katalizör kullanılarak esterleştirilebileceği açıklanmıştır [29]. Kullanılan yağın serbest yağ asidi değeri \%2 olarak belirlenmiş ve ilave alkali katalizör ile reaksiyon gerçekleştirilmiştir. Deneylerde kullanılan biyodizel asit değeri standartları karşılamaktadır. Motor test düzeneği, elektrikli DC tip dinamometre, sıkıştırma ile ateşlemeli motor, egzoz gaz analizörü ve duman ölçüm cihazından oluşmaktadır.

Şekil 1'de deney sistemi şematik olarak verilmiştir. Deneylerde tek silindirli, dört zamanlı sıkıştırma ile ateşlemeli motor kullanılmıştır. Deney motorunun teknik özellikleri Tablo 1'de verilmiştir. Aynı zamanda deney motoruna ilk hareketi vermek için de kullanılabilen DC dinamometre 4000 1/min'de 10kW güç absorbe edebilmektedir. Dinamometre yükü yük hücresi kullanılarak ölçülmüştür. Yakıt tüketimi, motorun $10 \mathrm{~mL}$ 'lik cam tüp içindeki yakıtı tüketme süresi belirlenerek ölçülmüştür. Egzoz sıcaklığı K tipi termoçift ile ölçülmüştür. Emisyon ölçümleri MRU DELTA 1600L egzoz gaz analizörü ile yapılmıştır. İs emisyonları MRU optrans 1600 duman ölçer ile belirlenmiştir. Analizörün ölçüm aralıkları ve hassasiyetleri Tablo 2'de verilmiştir. Deneyler motor çalışma sıcaklığına ulaştıktan sonra tam gaz ve değişik motor hızlarında (1800-3400 $1 /$ min) 200 $1 /$ min aralıklarla önce dizel yakıtı ile yapılmıştır. Daha sonra dizel+biyodizel karışımları test edilmiştir. Yakıt olarak Dizel yakıtı (DY), hacimsel olarak \%5 biyodizel $+\% 95$ dizel yakıtı (B5), \%20 biyodizel + $\% 80$ dizel yakıtı (B20), \%50 biyodizel $+\% 50$ dizel yakıtı karışımı (B50) ve \%100 biyodizel (B100) kullanılmıştır.

Tablo 3'te balık yağı metil esteri özellikleri, EN 14214 biyodizel standart değerleri ve ölçüm metotları birlikte verilmiştir. Yakıt özellikleri Tübitak MAM Enerji Enstitüsünde belirlenmiştir. Biyodizelin belirlenen özellikleri büyük oranda standartları karşılamaktadır. Fakat akma ve soğuk filtre tıkanma noktası dizel yakıtına göre daha yüksektir. Dolayısıyla bu metil esterin soğuk iklim ve kış şartlarında kullanılamayabileceğini veya dizel yakıtı ile belirli oranlarda karıştırılarak kullanılması önerilmektedir.

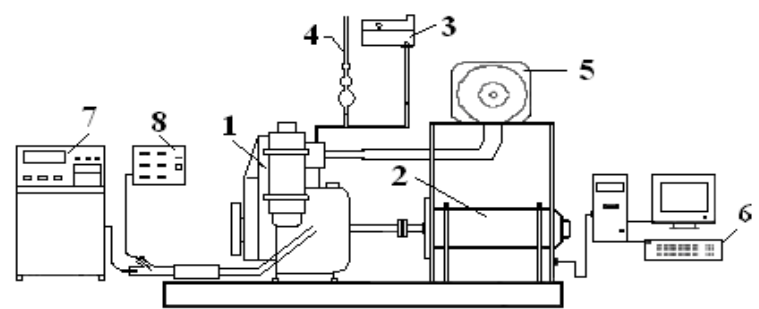

1-Motor, 2-Dinamometre, 3-Yakıt deposu, 4-Yakıt ölçme kabı, 5-Hava tankı 6-Kontrol ünitesi 7-Egzoz gaz analizörü, 8-Duman ölçer Şekil 1. Deney düzeneğinin şematik görüntüsü (Schematic view of the engine test bed).

Tablo 1. Deney motorunun teknik özellikleri (The technical specifications of the test engine).

\begin{tabular}{ll}
\hline Motor tipi & Dört zamanlı, direkt püskürtmeli dizel motor \\
\hline Silindir sayısı & 1 \\
Silindir çapı x strok & $78 \times 62 \mathrm{~mm}$ \\
Silindir hacmi & $296 \mathrm{~cm}^{3}$ \\
Maksimum motor gücü & $3,46 \mathrm{~kW}(36001 / \mathrm{min})$ \\
Sikıştırma oranı & $18: 1$ \\
Püskürtme basıncı & $200 \pm 5 \mathrm{bar}$ \\
\hline
\end{tabular}

Tablo 2. Egzoz gaz analizörünün özellikleri (The specifications of exhaust gas analyser).

\begin{tabular}{lll}
\hline Ölçüm & Ölçüm aralığı & Hassasiyet \\
\hline $\mathrm{CO}(\%$ vol $)$ & $0-15,00$ & $\pm \% 0,06$ \\
$\mathrm{CO}_{2}(\%$ vol $)$ & $0-20,00$ & $\pm \% 0,5$ \\
$\mathrm{NO}_{x}(\mathrm{ppm})$ & $0-2000$ & \pm 5 \\
$\mathrm{HC}(\mathrm{ppm})$ & $0-20000$ n-hexan & \pm 12 \\
Duman koyuluğu (\%) & $0-99$ & $\pm \% 2$ \\
\hline
\end{tabular}


Tablo 3. Deney yakıtlarının özellikleri (The properties of fuels used in the experiments) [1, 7].

\begin{tabular}{|c|c|c|c|c|}
\hline Özellik & BYME & Dizel Yakıtı & EN 14214 & Metot \\
\hline Yoğunluk, $\left(\mathrm{kg} / \mathrm{m}^{3}, 15^{\circ} \mathrm{C}\right)$ & 893,6 & 830,4 & $860-900$ & EN ISO 12185 \\
\hline Kinematik viskozite, $\left(\mathrm{mm}^{2} / \mathrm{s}, 40^{\circ} \mathrm{C}\right)$ & 4,708 & 2,853 & $3,5-5,0$ & EN ISO 3104 \\
\hline Parlama noktası, $\left({ }^{\circ} \mathrm{C}\right)$ & 163 & 62 & $\geq 120$ & EN ISO 3679 \\
\hline Karbon kalıntısı, \%(m/m) & - & $<0,1$ & $\leq 0,30$ & EN ISO 10370 \\
\hline Bakır Şerit Korozyonu, (3 saat $\left.50^{\circ} \mathrm{C}\right)$ & $1 \mathrm{a}$ & $1 \mathrm{a}$ & No.1 & EN ISO 2160 \\
\hline Kükürt, (mg/kg) & 7,2 & 9,7 & $\leq 10$ & EN ISO 20846 \\
\hline Setan sayısı & 55,8 & 55,2 & $\geq 51$ & EN ISO 5165 \\
\hline $\mathrm{Su},(\mathrm{mg} / \mathrm{kg})$ & 495 & 80 & $\leq 500$ & EN ISO 12937 \\
\hline Asit sayısı, (mgKOH/g) & 0,15 & - & $\leq 0,50$ & EN 14104 \\
\hline İyot Sayıs1 (g iyot/100g) & 93,9 & - & $\leq 120$ & EN 14111 \\
\hline Monogliserid içeriği (\%kütlesel) & 0,02 & - & $\leq 0,8$ & EN 14105 \\
\hline Digliserid içeriği (\%kütlesel) & 0,17 & - & $\leq 0,2$ & EN 14105 \\
\hline Trigliserid içeriği (\%kütlesel) & 0,12 & - & $\leq 0,2$ & EN 14105 \\
\hline Serbest gliserin (\%kütlesel) & $<0,01$ & - & $\leq 0,02$ & EN 14105 \\
\hline Toplam gliserin (\%kütlesel) & 0,042 & - & $\leq 0,25$ & EN 14105 \\
\hline 2. Grup metaller $(\mathrm{Ca}+\mathrm{Mg})(\mathrm{mg} / \mathrm{kg})$ & $<1,0$ & - & $\leq 5,0$ & EN 14538 \\
\hline Soğuk filtre tıkanma noktası $1\left({ }^{\circ} \mathrm{C}\right)$ & 1 & -10 & +5 (Yaz); -15 (Kış) & EN 116 \\
\hline Akma noktası,$\left({ }^{\circ} \mathrm{C}\right)$ & 4 & -12 & $\left.<4,0(\mathrm{Yaz}) ;<-1\left(\mathrm{~K}_{1}\right)\right)$ & ISO 3016 \\
\hline Bulutlanma noktası, $\left({ }^{\circ} \mathrm{C}\right)$ & 3 & -3 & - & EN 23015 \\
\hline Alt 1 sıl değer, $(\mathrm{kJ} / \mathrm{kg})$ & 38702 & 43220 & - & ASTM D240 \\
\hline Yağlama özelliği, $(\mu \mathrm{m})$ & 119 & 409 & - & EN ISO 12156-1 \\
\hline Karbon, $\%(\mathrm{~m} / \mathrm{m})$ & 72,01 & 80,97 & - & ASTM D 5373 \\
\hline Hidrojen, $\%(\mathrm{~m} / \mathrm{m})$ & 11,62 & 14,42 & - & ASTM D 5373 \\
\hline
\end{tabular}

İyot değeri yağın doymuşluk/doymamışlık değeri ile ilişkilidir. Hammaddeye göre farklılık gösterir. Hayvansal yağların iyot değeri düşüktür ancak düşük sıcaklıkta kolayca donma tehlikesi vardır. Yüksek iyot sayılı biyodizel tortu, aşırı karbon kalıntısı oluşumuna ve depolama kararlılığının düşmesine neden olmaktadır. Soğuk filtre tıkanma noktası, akma ve bulutlanma noktası gibi özelliklerinin dizel yakıtına göre yüksek olması, soğuk iklimlerde ve kış mevsiminde akış özelliklerini geliştirici katkılar ilave edilerek veya karışım halinde kullanılmasını gerektirmektedir [30, 31].

$\mathrm{Bu}$ çalışmada, biyodizel kaynağı olarak hamsi (Engraulis engrasicholus) yağı kullanılmıştır. Hamsinin yağ asitleri kompozisyonu literatürle [32] karşılaştırmalı olarak Tablo 4'te verilmiştir. Analiz sonuçlarında $\% 2$ 'den daha küçük yağ asiti değerleri toplamı diğerleri olarak belirtilmiştir. Analiz ve literatür sonuçlarının birbiriyle uyuştuğu gözlenmiştir. Hamsi yağının büyük oranda palmitik asit, oleik asit ve hexacosanoik asitten oluştuğu görülmüştür. Yapılan birçok çalışmada, mevcut çalışmaya benzer olarak palmitik asidin hamside en baskın doymuş yağ asidi olduğu bildirilmiştir. Hamside protein \%18, yağ \%7-13 ve nem içeriği ise \%77-66 civarında olduğu ve mevsime, yaşadığı ortama (sıcaklık, tuzluluk) ve beslenmesine göre değiş̧iklik gösterdiği açıklanmıştır. Yine, hamsilerdeki yağ ve nem içeriği arasında ters bir ilişkinin var olduğu bildirilmiştir. Kasım ayında avlanan balıkların yağ oranının yüksek nem oranının düşük olduğu açıklanmıştır [32-34].
Tablo 4. Hamsinin yağ asitleri kompozisyonu (Fatty asit composition of anchovy).

\begin{tabular}{lll}
\hline Fatty acid (\%) & Analiz & {$[\mathbf{3 2}]$} \\
\hline Miristik (C14:0) & 6,5 & 6,575 \\
Palmitik (C16:0) & 21,6 & 18,725 \\
Palmitoloik (C16:1) & 6,7 & 6,900 \\
Stearik (C18:0) & 4,1 & 3,610 \\
Oleik (C18:1) & 18,6 & 13,040 \\
Linoleik (C18:2) & 2,4 & 4,465 \\
Arachidonik asit (C20:5n-3) & 9,4 & 10,545 \\
Hexacosanoik asit (C22:6) & 16,0 & 17,685 \\
Diğerleri & 14,8 & 18,454 \\
\hline
\end{tabular}

Hamsi (Engraulis encrasicolus), Engraulidae familyasından, ince bir vücuda sahip, alt dudağı olmayan, üst çenesi ise uzun, sırt rengi koyu mavi siyahımsı, alt taraf açık renkli, yan tarafları parlak olan ve dünya denizlerinde çeşitli türleri bulunan, ülkemizde Karadeniz ve Marmara Denizinde sürüler halinde yaşayan $20 \mathrm{~cm}$ 'ye kadar büyüyen göçmen bir balık türüdür [35]. 2011 yllı Türkiye İstatistik Enstitüsü verilerine göre Türkiye'de 703545,2 ton deniz, tatlısu ve kültür balıkları ile diğer deniz ürünleri üretilmekte ve bunların 432246 tonunu deniz balıkları ve bunların da 228491,4 tonunu hamsi oluşturmaktadır [36]. 2010 FAO verilerine göre ise, dünyada toplam 150 milyon ton balık üretimi yapilmaktadır.

\section{BULGULAR VE TARTIŞMA (RESULTS AND DISCUSSION)}

Biyodizel bitkisel, atık ve hayvansal yağlardan üretilebilen; oksijen içerikli, sülfür içermeyen, zehirleyici olmayan, bozunabilir, yüksek setan sayılı ve yağlayıcılık özellikli yenilenebilir alternatif bir 
yakıttır. Özellikleri dizel yakıtına oldukça yakın olduğundan dizel motorda herhangi bir değişiklik yapılmadan doğrudan veya karıșım halinde kullanılabilmektedir. Yağlama özelliğini iyileştirmesinden dolayı \%2, yağlama özelliğini iyileştirmesinin yanında egzoz emisyonlarını azaltmaya yardımcı olmasından dolayı \%20 oranında dizel yakıta karıştırılarak kullanılmaktadır. Ayrıca, her iki faydayı sağlamakla birlikte ucuz ve yeterli miktarda temin edilebilmesi halinde doğrudan kullanımı mümkündür. Bu deneysel çalışmada, balık yağı metil esteri ve dizel yakıtı (DY) ile karışımları hacimsel olarak $\% 5,20,50$ ve 100 oranlarında bir dizel motorda kullanılarak moment, efektif güç, özgül yakıt tüketimi, $\mathrm{CO}, \mathrm{HC}, \mathrm{NO}_{x}$ ve duman koyuluğuna etkisi karşılaştırmalı olarak verilmiştir. Biyodizelin doğrudan veya dizel yakıtı ile karışımlarının kullanımı sırasında ve sonrasında motorda ve yakıt sisteminde herhangi bir problem görülmemiştir. Önceki çalışmalarda da çeşitli kaynaklardan üretilen biyodizelin doğrudan veya dizel yakıtı ile karışımlarının motor performansı ve egzoz emisyonlarına etkileri araștırılmıștır [37]. Şekil 2'de dizel ve biyodizel yakıtları ve karışımlarının motor momenti ve gücüne etkisi görülmektedir.

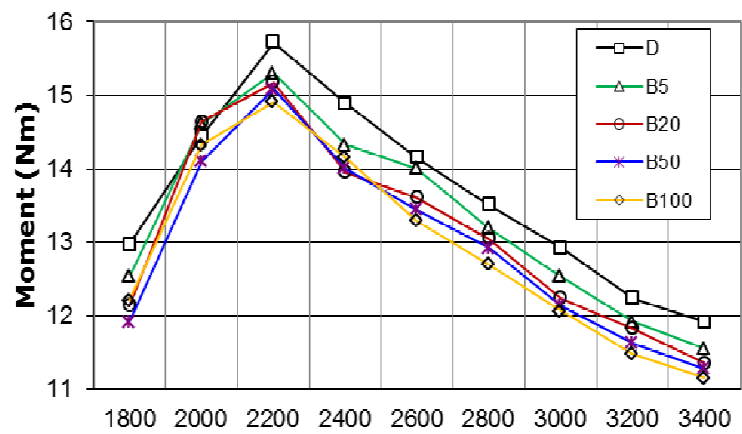
Motor Hızı $(1 / \mathrm{min})$

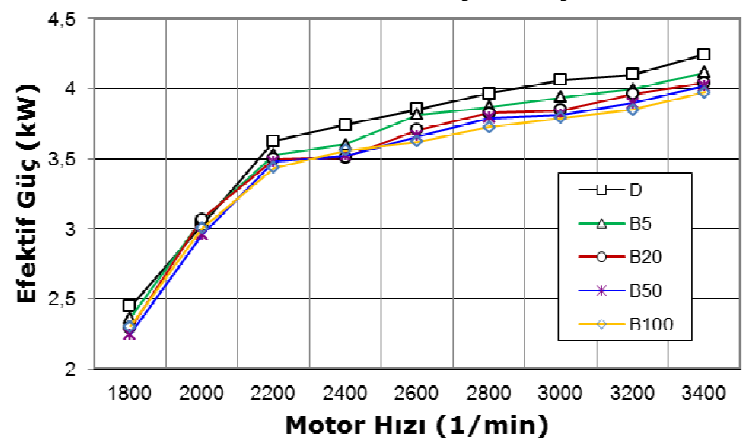

Şekil 2. Dizel ve biyodizel yakıt ve karışımlarının motor momenti ve gücüne etkisi (The effect of diesel and biodiesel fuel blends on engine torque and power).

Biyodizelin hem saf, hem de dizel yakıtına ilave edilmesi ile moment ve efektif güçte \%2-6 arasında değişen oranlarda azalmalar belirlenmiştir. Azalmaların karışımdaki biyodizel miktarı ile orantılı olarak değiştiği görülmektedir. Biyodizel yakıtının 1sıl değerinin dizel yakıtından düşük olması moment ve efektif güçteki azalmanın temel nedenidir. Biyodizel yakıtların oksijen içeriği ve yüksek setan sayısı nedeniyle özellikle zengin karışım bölgelerinde daha iyi yanma sağlaması, yoğunluğunun yüksek olması aynı hacimde pompanın kütlesel olarak daha fazla yakıt püskürtmesi ve viskozitesinin yüksek olması nedeniyle de pompa ve enjektör kaçaklarının az olması moment ve efektif güçte gerçekleşebilecek azalmaları kısmen karşılamaktadır. Benzer sonuçlar diğer araştırmacılar tarafindan da açıklanmıştır [38, 39]. Şekil 3'te dizel ve biyodizel yakıtların özgül yakıt tüketimine etkisi görülmektedir. Birim güç başına saatte tüketilen yakıt miktarı özgül yakıt tüketimi olarak ifade edilmekte ve motorların karşılaştırılmasında önemli bir parametre olarak görülmektedir. Biyodizel ilavesi özgül yakıt tüketiminde artışa sebep olmaktadır. Özgül yakıt tüketimindeki bu artışın dizel yakıtının içerisine biyodizel ilavesiyle orantılı olduğu görülmektedir.

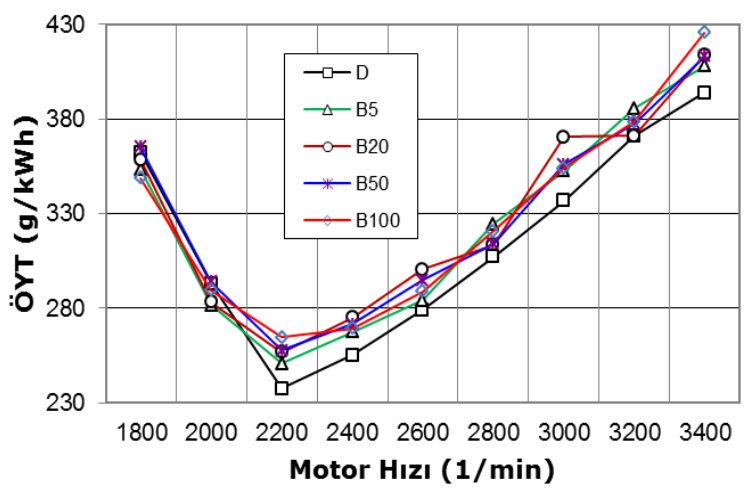

Şekil 3. Dizel ve biyodizel yakıt ve karıșımlarının özgül yakıt tüketimine etkisi (The effect of diesel and biodiesel fuel blends on specific fuel consumption).

Biyodizel karışımı ile çalışmalarda, özgül yakıt tüketimi dizel yakıta göre daha yüksektir. Dizel yakıtı ve balık yağı metil esterleri ile minimum özgül yakıt tüketiminin ölçüldüğü $2200 \quad 1 /$ min'de ölçülmüştür. (B5), (B20), (B50) ve (B100) kullanımında özgül yakıt tüketiminde dizel yakıtı kullanımına göre ortalama olarak \%5-12 arasında artış olduğu belirlenmiştir. Biyodizel yakıtının 1sıl değerinin dizel yakıtınkinden düşük olması nedeniyle aynı miktarda enerji elde etmek için daha fazla yakıt kullanmak gerekmektedir. Bu durum özgül yakıt tüketimlerinin dizel yakıta göre daha yüksek olmasının temel nedenidir [40, 41]. Ayrıca, püskürtülen yakıtın yoğunluğu, miktarı ve viskozitesi özgül yakıt tüketimini etkilemektedir. Viskozite ve yoğunluk gibi yakıt özellikleri yakıtın atomizasyon kalitesini etkilemektedir [42, 43].

Dünya nüfusunun artışı, güç santralleri, fabrikalar ve taşıtların artışı enerji talebini ve tüketilen yakıt miktarını artırdığından hava kabul edilemez şekilde kirletilmeye başlanmıştır. Bu kirliliği azaltmak için kaynağından önce, kaynağında ve yanma sonrası yöntemler uygulanmaktadır. Alternatif yakıtlar ile kirletici emisyonların azaltılması bir yöntem olarak değerlendirilmektedir. Şekil 4'te, CO emisyonun 
motor devri ve yakıt türüne göre değişimi görülmektedir. CO yakıttaki karbonun tamamen yanamaması sonucu oluşan renksiz, kokusuz, tatsız ve havadan yaklaşık \%3 daha hafif bir kirletici ve solunduğunda oldukça zehirli bir gazdır. DY'den B100 kullanımına doğru gidildikçe CO emisyonunda azalma olduğu dikkati çekmektedir. Tüm motor hızlarında (B100), (B50), (B20) ve (B5) kullanımı ile CO emisyonunda DY'ye kıyasla \%4-14 arasında değişen oranlarda azalmalar belirlenmiştir. Bu durum, biyodizel ve karışımlarının özgül yakıt tüketiminin DY'ye oranla daha yüksek olmasına rağmen gerçekleşmiştir. Biyodizel ve karışımlarının kullanılması ile CO emisyonundaki azalmanın temel nedeni biyodizel yakıtının oksijen içermesiyle yanma sırasında yakıtın oksidasyonunu artırması ve dolayısı ile de $\mathrm{CO}$ emisyonlarının $\mathrm{CO}_{2}$ dönüşmesine olumlu etkide bulunması, düşük hidrojen/karbon oranı ve yüksek setan sayısıdır. Benzer sonuçlar diğer araştırmacılar tarafindan da açıklanmıştır [39, 40].

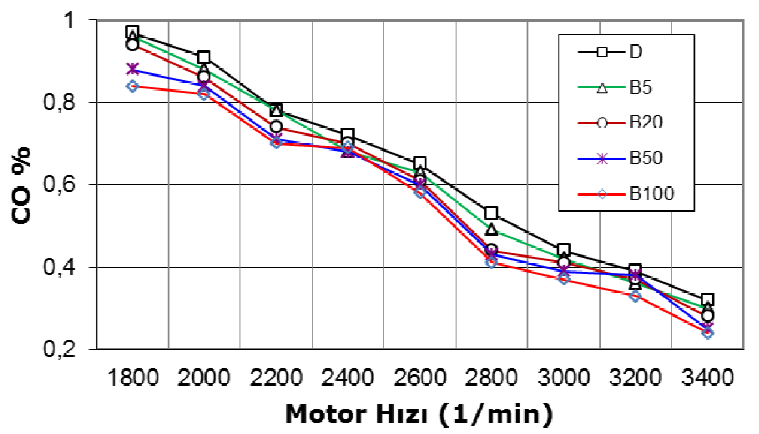

Şekil 4. Dizel ve biyodizel yakıt ve karışımlarının CO emisyonuna etkisi (The effect of diesel and biodiesel fuel blends on $\mathrm{CO}$ emisssions).

Şekil 5'te motor hızına bağlı olarak dizel ve biyodizel yakıtlarının $\mathrm{HC}$ emisyonlarının değişimi görülmektedir. Genel olarak, HC oksijen eksikliği veya tamamlanmamış yanma işleminden kaynaklanmakta ve beyin hücrelerine ve solunum sistemine zarar vermektedir. Yakıt bileşenleri, yanma odası geometrisi, hava-yakıt oranı, boşluk hacimleri, supap bindirmesi, yanma odası duvarlarındaki yağ ve kalıntılar, egzoz supabından kaçaklar gibi motor tasarım ve çalışma parametrelerinden etkilenmektedir.

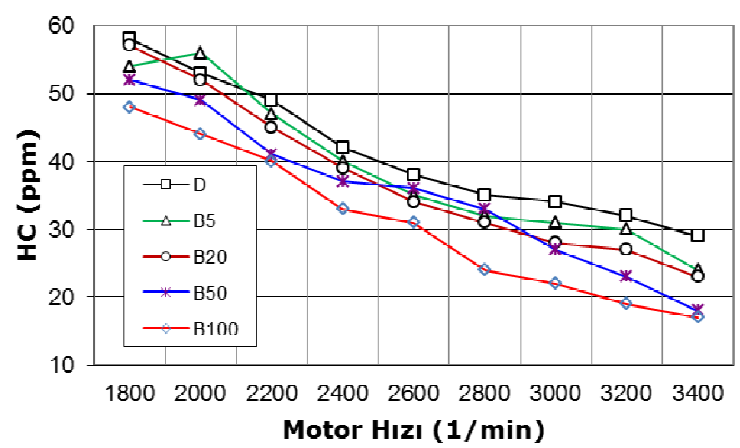

Şekil 5. Dizel ve biyodizel yakıt ve karışımlarının HC emisyonuna etkisi (The effect of diesel and biodiesel fuel blends on $\mathrm{HC}$ emissions).
Tam yük şartlarında, tüm devirlerde biyodizel ve karışımlarının kullanılmasıyla elde edilen yanmamış HC emisyonu DY'ye göre daha düşük seviyededir. Dizel yakıtına balık yağı metil esteri ilave edilmesi ile (B5, B20, B50 ve B100) HC emisyonunda dizel yakitı kullanımına göre ortalama olarak \%5-25 arasında değişen oranlarda azalmalar olduğu belirlenmiştir. Dizel motorlarda, yakıt jeti etrafinda tutuşması zor oldukça fakir karışımlar, enjektör iğnesi etrafinda ve püskürtme deliklerinde kalan yakıt (genişleme periyodu esnasında silindire girerek eksik oksijen sebebiyle yanamazlar) yanmamış $\mathrm{HC}$ emisyonlarının temel kaynaklarıdır [6]. Ayrıca, CO ve HC konsantrasyonları motor hızındaki artış ile türbülans arttığından azalmaktadır. Şekil 6'da motor devrine bağlı olarak dizel, biyodizel ve karışımlarının $\mathrm{NO}_{\mathrm{x}}$ emisyonlarının değişimi görülmektedir.

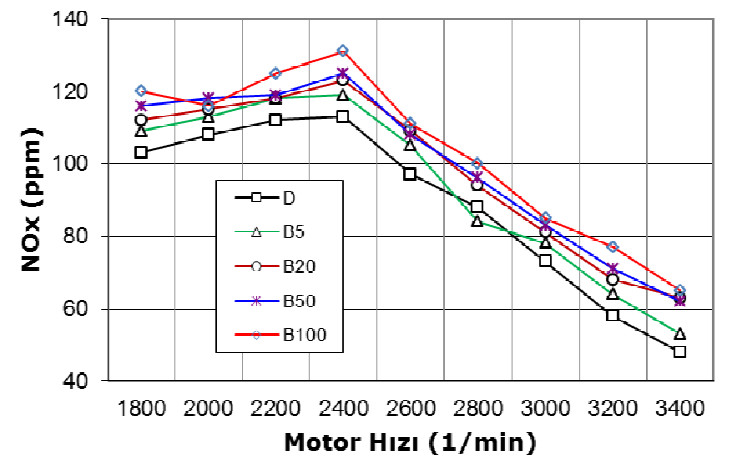

Şekil 6. Dizel ve biyodizel yakıtlarının ve karışımlarının $\mathrm{NO}_{\mathrm{x}}$ emisyonlarınına etkisi (The effect of diesel biodiesel fuel and their blends on $\mathrm{NO}_{\mathrm{x}}$ emissions).

Azotoksit $\left(\mathrm{NO}_{x}\right)$ diesel motorlardan kaynaklanan zararlı emisyonlardan birisidir. $\mathrm{NO}_{x}$ oluşumu oldukça karmaşık olmasına rağmen sıcaklığa, bölgesel oksijen konsantrasyonuna ve yanma süresine bağlıdır. Yük, sıkıştırma oranı, doldurma seviyesi, dolgu sıcaklığı, enjeksiyon zamanlaması, nozul tasarımı veya karışım oluşumu, silindir pik basıncı, setan sayısı gibi çalışma ve tasarım parametreleri ise $\mathrm{NO}_{x}$ oluşumunda daha etkili olan yanma sicaklığ ve oksijen konsantrasyonunu etkilemektedir. $\mathrm{NO}_{x}$ olarak isimlendirilen kirleticiler, yanma sirasinda, azot monoksit $(\mathrm{NO})$ ve azot dioksit $\left(\mathrm{NO}_{2}\right)$ olarak ortaya çıkmaktadırlar. Yanma işlemi sırasında çoğunlukla $\mathrm{NO}$ üretilir. $\mathrm{NO}_{2}$ kırmızımsı-kahverengi keskin kokulu bir gaz iken, NO renksiz ve kokusuz bir gazdır. Her ikiside zehirlidir, ancak $\mathrm{NO}_{2} \mathrm{NO}$ 'dan daha çok zehirlidir. $\mathrm{NO}_{x}$ solunum sisteminde astım, akciğer kanseri ve kalp ve damarlara ilişkin ciddi sağlık problemlerine neden olmaktadır. Ayrıca, yer seviyesi ozonu, asit ayresolları, asit yağmurları, toksik kimyasallar ve su kalitesinin bozulması gibi çevreye zarar verici etkilere sahiptir [17, 40]. Biyodizel ve karışımları ile çalışmalarda, $\mathrm{NO}_{x}$ emisyon değerleri dizel yakıta göre daha yüksektir. Dizel yakıtına balık yağ1 metil esteri ilave edilmesi ile B5, B20, B50 ve B100 kullanımında $\mathrm{NO}_{x}$ emisyonlarında dizel yakıtı kullanımına göre ortalama olarak \%7-17 arasında 
değişen oranlarda artış olduğu belirlenmiştir. Biyodizelin içeriğindeki oksijenin yakıtça zengin bölgelerde gerekli oksijeni sağlaması, tam yanma bölgelerinin sayısını artırmaktadır. Böylece, yüksek ortam sıcaklığının elde edildiği bölge sayısı arttığından, daha yüksek miktarda azot oksit oluşumu gerçekleşebilmektedir [38]. Şekil 7'de motor devrine bağlı olarak dizel yakıtı, biyodizel ve karışımlarının is emisyonları değişimi görülmektedir. Biyodizel ile çalışmalarda karışımdaki biyodizel miktarı ile orantılı olarak is emisyonunda azalmalar belirlenmiştir. Bu durum, biyodizelin oksijen içeriğinin yanma bölgelerinde gerekli oksijeni sağlayarak silindir içerisindeki oksitlenme miktarını artırması ile açıklanabilir. Ayrıca, biyodizelin hemen hemen hiç aromatik bileşik içermemesi partikül ve is emisyonlarında önemli azalmalar sağlamaktadır. Sonuçlar önceki çalışmalar ile uyum göstermektedir [5, 41]. Diğger taraftan, devir artışı ile hem karışım oluşumu hem de yakıtın atomizasyonu gelişmekte ve is emisyonları azalmaktadır.

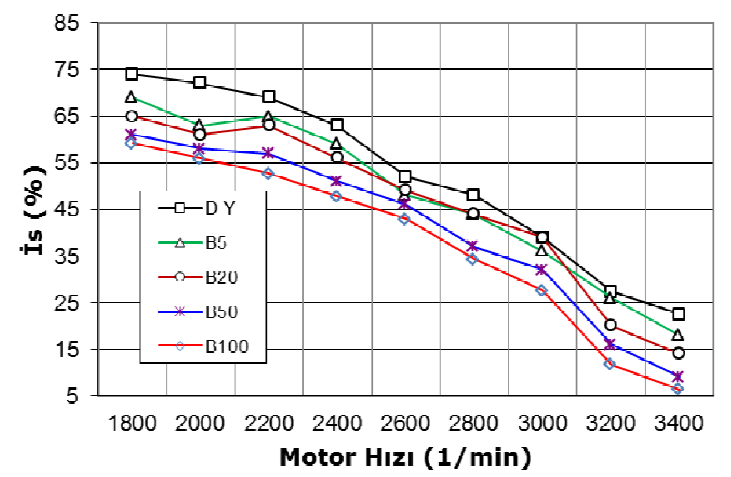

Şekil 7. Dizel ve biyodizel yakıtları ve karışımlarının is emisyonlarına etkisi (The effect of diesel, biodiesel fuel and their their blends on smoke density).

\section{SONUÇLAR (CONCLUSIONS)}

Fosil kökenli yakıtların çevreye verdikleri zararların yanı sira son zamanlarda fiyatlarında meydana gelen artışlar, bu yakıtların yerini alabilecek yenilenebilir enerji kaynaklarının önemini daha da artırmıştır. Bunlardan bir tanesi olan biyodizel, bitkisel veya hayvansal yağlardan üretilen, dizel motorlarında hiçbir değişiklik yapılmadan kullanılabilen, çevreye karşı daha duyarlı ve yenilenebilir özelliğe sahip alternatif dizel yakıttır. Yüksek kaliteli bitkisel yağların biyodizel üretiminde kullanılması, biyodizeli motorine oranla daha pahalı hale getirmektedir. $\mathrm{Bu}$ nedenle daha düşük maliyetli hammaddelere ihtiyaç duyulmaktadır. Hayvansal yağlar biyodizel üretimi için ilgi çeken hammaddelerdir. $\mathrm{Bu}$ araştırmada, hamsi yağından biyodizel üretilmiş ve balığın atık kısımlarının ve talep fazlasının biyodizel kaynağ 1 olarak değerlendirilebileceği vurgulanmıştır. Üretilen BYME dizel yakıtı ile hacimsel olarak $\% 5, \% 20, \% 50$ oranlarında harmanlanarak ve $\% 100$ oranında tek silindirli, dört zamanlı, hava soğutmalı bir dizel motorda test edilmiştir. Motor testleri tam yükte ve değişik motor devirlerinde (1800-3400 1/min) 200 $1 /$ min aralıklarla test edilmiş aşağıdaki sonuçlar belirlenmiştir. Biyodizel dizel motorlarda herhangi bir ayar ve değişiklik yapılmadan saf veya dizel yakıtı ile karıştırılarak kullanılabilmektedir. Balık yağı metil esteri ve karışımlarının dizel yakıta benzer özellikler göstermesi ve egzoz emisyonlarını azaltıcı yönde etkilerinden dolayı dizel motorlarda alternatif bir yakıt olarak kullanılabilecektir. Balık atıklarının ve atık yağların biyodizele dönüştürülerek kullanılması çevreci bir yaklaşım olarak değerlendirilmektedir. Sıfır atık gıda politikası düşünüldüğünde, dünya genelinde üretilen balığın azımsanmayacak kısmı atık olarak ayrılmaktadır. Ayrıca, biyodizelin dezavantajlarından biri olan yüksek maliyeti azaltması açısından oldukça önemlidir. Biyodizelin 1sıl değerinin dizel yakıta göre daha düşük olmasından dolayı moment ve efektif güçte azalma, özgül yakıt tüketiminde artış belirlenmiştir. Biyodizelin oksijen içeriği, düşük hidrojen/karbon oranı ve yüksek setan sayısı dolayısıyla $\mathrm{CO}, \mathrm{HC}$ ve is emisyonlarında, azalma belirlenmiştir. Silindir sıcaklıklarının artması ve biyodizelin oksijen içeriği nedeniyle $\mathrm{NO}_{\mathrm{x}}$ emisyonlarında artış görülmüştür.

\section{TEŞEKKÜR (ACKNOWLEDGEMENT)}

Bu çalışma, Karabük Üniversitesi Bilimsel Araştırma Projeleri Birimi tarafindan 2012-70-01-01'nolu proje ile desteklenmiştir. Yakıt analizleri Tübitak Mam Enerji Enstitüsünde yapılmıştır. KBÜ Bilimsel Araştırma Projeleri Birimi ve Tübitak Mam Enerji Enstitüsüne teşekkür ederiz. Ayrıca, Sürsan $\mathrm{Su}$ Ürünleri Fabrikasına çalışmanın ana materyali konusundaki desteklerinden dolayı teşekkür ederiz.

\section{KAYNAKLAR (REFERENCES)}

1. Keskin, A., Gürü, M., Altıparmak, D., "Influence of tall oil biodiesel with $\mathrm{Mg}$ and Mo based fuel additives on diesel engine performance and emission", Bioresource Technology, Cilt 99, 6434-6438, 2008.

2. Çelikten İ., Gürü M., "Improvement of performance and emission criterias of petrodiesel and rapeseed oil biodiesel with manganese based additive", Journal of the Faculty of Engineering and Architecture of Gazi University, Cilt 26, No 3, 643-648, 2011.

3. Gürü, M., Artukoğlu, B.D., Keskin, A., Koca, A., "Biodiesel production from waste animal fat and improvement of its characteristics by synthesized nickel and magnesium additive", Energy Conversion and Management, Cilt 50, 498-502, 2009.

4. Yahyaee, R., Ghobadian, B., Najafi, G., "Waste fish oil biodiesel as a source of renewable fuel in Iran", Renewable and Sustainable Energy Reviews, Cilt 17, 312-319, 2013. 
5. Gürü, M., Koca, A., Can, Ö., Çınar, C., Şahin, F., "Biodiesel production from waste chicken fat based sources and evaluation with $\mathrm{mg}$ based additive in a diesel engine", Renewable Energy, Cilt 35, No 3, 637-643, 2010.

6. Sekmen, Y., "Use of watermelon and flax seed oil methyl esters as a fuel in a diesel engine", Technology, Cilt 10, No 4, 295-302, 2007.

7. Sekmen, Y., Aktaş, A., "Effects of soybean oil methyl ester on diesel engine performance and exhaust emissions' Journal of Polytechnic, Cilt 11, No 3, 249-254, 2008.

8. Çengelci, E., Bayrakçeken, H., Aksoy, F., "Effect of animal fat methyl ester usage on engine performance and emissions in a diesel engine", 6th International Advanced Technologies Symposium (IATS'11), Elazı̆g, 113-116, 2011.

9. Aktaş, A., Sekmen, Y., "The effects of advance fuel injection on engine performance and exhaust emissions of a diesel engine fuelled with biodiesel", Journal of the Faculty of Engineering and Architecture of Gazi University, Cilt 23, No 1, 199-206, 2008.

10. Canakci, M., "Combustion characteristics of a turbocharged DI compression ignition engine fueled with petroleum diesel fuels and biodiesel", Bioresource Technology, Cilt 98, 1167-1175, 2007.

11. Behçet, R., Çakmak, A.V., "Effect of fish oil methyl ester blends on engine performance and emissions in a diesel engine", 6th International Advanced Technologies Symposium (IATS'11), Elazı̆̆g, 161-165, 16-18 May, 2011.

12. Zhang, J., Chen, S., Yang, R. Yan, Y., "Biodiesel production from vegetable oil using heterogenous acid and alkali catalyst", Fuel, Cilt 89, 29392944, 2010.

13. Yücesu, H.S., Altın, R., Çetinkaya, S., "Experimental investigation of vegetable oil usage as alternative fuel in diesel engine", Turk J Engin Environ Sci, Cilt 25, 39-49, 2001.

14. No, S.Y., "Inedible vegetable oils and their derivatives for alternative diesel fuels in CI engines", Renewable and Sustainable Energy Reviews, Cilt 15, 131-149, 2011.

15. Aziz AA., Said, MF., Awang, MA., "Performance of palm oil- based biodiesel fuels in a single cylinder direct injection engine", Malaysian Palm Oil Development, Cilt 42, 1527, 2005.

16. Monyem, A., Van Gerpen, JH., "The effect of biodiesel oxidation on engine performance and emissions", Biomass and Bioenergy, Cilt 20, 317-325, 2001.

17. Fernando, S., Hall C., Jha, S., "NOx reduction from biodiesel fuels", Energy and Fuels, Cilt 20, 376-382, 2006.

18. Kegl B., "Experimental investigation of optimal timing of the diesel engine injection pump using biodiesel", Energy and Fuels, Cilt 20, 14601470, 2006.
19. Dorado, MP., Ballesteros E., Arnal, JM., Gomez, J., Lopez, FJ., "Exhaust emissions from a diesel engine fuelled with transesterified waste olive oil", Fuel, Cilt 82, No 11, 1311-1315, 2003.

20. Kalam, MA., Masjuki, HH., "Biodiesel from palm oil an analysis of its properties and potential", Biomass Bioenergy, Cilt 23, 471-479, 2002.

21. Lin, CY., Huang, JC., "An oxygenating additive for improving the performance and emission characteristics of marine diesel engines", Ocean Engineering, Cilt 30, 1699-1715, 2003.

22. Buyukkaya, E., Benli, S., Karaaslan, S., Guru, M., "Effects of trout-oil methyl ester on diesel engine performance and emission characteristics", Energy Conversion and Management, Cilt 69, 41-48, 2013.

23. Şen, S., "Biodiesel production from animal fats and investigating their effect on diesel engine performance and emissions", M. Sc. Thesis, Karabuk University, Graduate School of Natural and Applied Sciences, 2012.

24. Reyes, J.F., Sepülveda, M.A., "Pm-10 emissions and power of a diesel engine fueled with crude and refined biodiesel from salmon oil", Fuel, Cilt 85, 12-13, 1714-1719, 2006.

25. Godiganur, S., Murthy, C.S., Reddy, R.P., "Performance and emission characteristics of a Kirloskar HA394 diesel engine operated on fish oil methyl esters", Renewable Energy, Cilt 35, No 2, 355-359, 2010.

26. Akçay, M., Sekmen, Y., Yılmaz, İT., Gölcü, M., Yazıc1, H., "The place of free fatty acids and water in biodiesel production process from waste oils," International Scientific Conference (UNITECH'10), Gabrova, Bulgaria, 574-578, 1920 November 2010.

27. Canakcı M., The potential of restaurant waste lipids as biodiesel feedstocks, Bioresource Technology, Cilt 98, 183-190, 2007.

28. Ramadhas AS., Jayaraj S., Muraleedharan C., Biodiesel production from high FFA rubber seed oil, Fuel, Cilt 84, 335-340, 2005.

29. Van Gerpen J., Biodiesel processing and production, Fuel Processing Technology, Cilt 86, 1097-1107, 2005.

30. Echim, C., Maes, J., Greyt, WD., "Improvement of cold filter plugging point of biodiesel from alternative feedstocks", Fuel, Cilt 93, 642-8, 2012.

31. Usta, N., Aydogan, B., Con AH., Uguzdogan, E., Ozkal, SG., "Properties and quality verification of biodiesel produced from tobacco seed oil", Energy Conversion and Management, Cilt 52, No 5, 2031-9, 2011.

32. Olgunoğlu, İ.A., "Sensory chemical and microbiological changes of marinated anchovy (Engraulis engrasicholus L., 1758)", $\mathrm{PhD}$. Thesis, University of Cukurova, Institute of Natural and Applied Sciences, 2007. 
33. Gökoğlu, N. , Özden Ö., Erkan, N., Taçnur T., Metin, B., Metin, S., "Seasonal variation in fat content of anchovy (Engraulis encrasicolus)", International Journal of Food Science and Technology, Cilt 34, 401-402, 1999.

34. Özden, Ö., "Changes in amino acid and fatty acid composition during shelf-life of marinated fish", Journal of the Science of Food and Agriculture, Cilt 85, 2015-2020, 2005.

35. Cascado, S.P.S., Vidal-Carou, M.C., Nunes, M.L., "Veciananogués, M.T., Sensory analysis to assess the frehness of Mediterranean anchovies (Engraulis encrasicholus) stored in ice", Food Control, Cilt 17, 564-569, 2006.

36. TÜİK su ürünleri istatistikleri, 2011. http://www.tuik.gov.tr/PreHaberBultenleri.do?id $=10863$, 29.05.2013.

37. Ghazali, W.N.M.W., Mamat, R., Masjuki, H.H., Najafi, G., "Effects of biodiesel from different feedstocks on engine performance and emissions: A review", Renewable and Sustainable Energy Reviews, Cilt 51, 585-602, 2015.

38. Usta N., "An experimental study on performance and exhaust emissions of a Diesel engine fuelled with tobacco seed oil methyl ester", Energy Conversion and Management, Cilt 46, No 1516, 2373-86, 2005.
39. Özcanlı, M., Keskin, A., Aydın, K., "Biodiesel production from terebinth (pistacia terebinthus) oil and its usage in diesel engine", International Journal of Green Energy, Cilt 8, No 5, 518528, 2011.

40. Abdel-Rahman, AA., "On the emissions from internal-combustion engines: a review", International Journal of Energy Research, Cilt 22, No 6, 483-513, 1998.

41. Kumar, MS., Kerihuel, A., Belletre, J., Tazerout, M., "Experimental investigations on the use of preheated animal fat as fuel in a compression ignition engine", Renewable Energy, Cilt 30, No 1, 1445-1456, 2005.

42. Usta, N., Öztürk, E., Can, Ö., Conkur, ES., Nas, S., Çon, AH., Can, AÇ., Topcu, M., "Combustion of biodiesel fuel produced from hazelnut soapstock/waste sunflower oil mixture in a Diesel engine", Energy Conversion and Management, Cilt 46, No 5, 741-755, 2005.

43. Özsezen, AN., Çanakçi, M., Turkcan, A., Sayin, C., "Performance and combustion characteristics of a DI diesel engine fueled with waste palm oil and canola oil methyl esters", Fuel, Cilt 88, No 4, 629-636, 2009. 
